\title{
Discovery of a Lead Triphenylethanamine Cholesterol Ester Transfer Protein (CETP) Inhibitor
}

\author{
Heather J. Finlay, ${ }^{*}{ }^{\dagger}$ ○ Ji Jiang, ${ }^{\dagger}$ Richard Rampulla, $^{\dagger}$ Mark E. Salvati, $^{\dagger}$ Jennifer X. Qiao, ${ }^{\dagger}$
} Tammy C. Wang, ${ }^{\dagger}$ R. Michael Lawrence, ${ }^{\dagger}$ Lalgudi S. Harikrishnan, ${ }^{\dagger}$ Muthoni G. Kamau, ${ }^{\dagger}$ David S. Taylor, ${ }^{\ddagger}$ Alice Ye A. Chen, ${ }^{\ddagger}$ Xiaohong Yin, Christine S. Huang, ${ }^{\S}$ Ming Chang, Xue-Qing Chen," Paul G. Sleph, ${ }^{\ddagger}$ Carrie Xu, ${ }^{\perp}$ Julia Li, ${ }^{\ddagger}$ Paul Levesque, ${ }^{\ddagger}$ Leonard P. Adam, and Ruth R. Wexler ${ }^{\dagger}$

Departments of ${ }^{\dagger}$ Discovery Chemistry, ${ }^{\ddagger}$ Biology, ${ }^{\S}$ Preclinical Candidate Optimization, ${ }^{\|}$Pharmaceutics, and ${ }^{\perp}$ Bioanalytical Sciences, Bristol-Myers Squibb, Research and Development, P.O. Box 5400, Princeton, New Jersey 08543-5400, United States

\section{Supporting Information}

ABSTRACT: Lead optimization of the diphenylpyridylethanamine (DPPE) and triphenylethanamine (TPE) series of CETP inhibitors to improve their pharmaceutical profile is described. Polar groups at the $N$-terminus position in the DPPE series resulted in further improvement in potency and pharmaceutical properties concomitant with retaining the safety, efficacy, and pharmacokinetic (PK) profile. A structure-activity relationship observed in the DPPE series was extended to the corresponding analogs in the more potent TPE series, and further optimization resulted in the identification of 2-amino- $N$-( $(R)$-1-(3-cyclopropoxy-4-fluorophenyl)-1-(3-fluoro-5-(1,1,2,2-tetrafluoroethoxy)phenyl)-2-phenylethyl)-4,4,4-trifluoro-3-hydroxy-3-(trifluoromethyl)butanamide (13). Compound 13 demonstrated no significant changes in either mean arterial blood pressure or heart rate in telemetry rats, had an excellent PK profile, and demonstrated robust efficacy in human CETP/apo-B-100 dual transgenic mice and in hamsters.

KEYWORDS: Diphenylpyridylethanamine, triphenylethanamine, CETP, coronary heart disease
A therosclerosisis a hallmark of coronary heart disease (CHD) characterized by the formation of cholesterol laden plaques that lead to the thickening of the arterial wall, decreased blood flow, and increased propensity for rupture resulting in acute clinical events such as myocardial infarction. ${ }^{1,2}$ Uptake of modified low-density lipoprotein cholesterol (LDL-C) particles by macrophages in the arterial wall contributes to the formation of plaque, and there is a wellestablished correlation between circulating levels of LDL-C and the risk of $\mathrm{CHD} .^{3}$ Current lipid modifying therapies for the treatment of $\mathrm{CHD}$ target lowering circulating levels of LDL-C via inhibition of the 3-hydroxy-3-methyl-glutarylcoenzyme A reductase ${ }^{4}$ and Niemann-Pick C1-Like 1 (NPC1L1) inhibition. ${ }^{5}$ Reverse cholesterol transport (RCT) is the process of transferring cholesterol from peripheral cells (especially those in the arterial wall) to high density lipoprotein (HDL) and then LDL in the circulation, followed by uptake in the liver and biliary excretion. Increasing highdensity lipoprotein (HDL) is known to facilitate $\mathrm{RCT}^{6}{ }^{6}$ and there is an inverse correlation between the levels of circulating HDL-C and CHD. ${ }^{3}$ These observations suggest that agents, which increase HDL-C, have the potential to be beneficial for CHD due, in part, to their effects on RCT, but potentially also due to other antiatherosclerotic effects that have been ascribed to HDL. ${ }^{7}$ Currently approved therapies (e.g., Niacin) demonstrate relatively modest effects on HDL-C levels and are of questionable benefit to patients with $\mathrm{CHD}{ }^{8}$

The plasma glycoprotein cholesterol ester transfer protein (CETP) is secreted by the liver and mediates the net transfer of cholesterol ester from HDL to LDL and VLDL in exchange for triglycerides. ${ }^{9}$ Inhibition of CETP by small molecule inhibitors such as anacetrapib, ${ }^{10}$ evacetrapib, ${ }^{11}$ and antisense oligonucleotides $^{12}$ has resulted in reduced LDL-C and increased HDL-C levels in the clinic. However, it has not yet been demonstrated that increasing HDL-C levels through this mechanism, which should enhance RCT from the periphery, is antiatherosclerotic. The phase III study with evacetrapib was terminated due to lack of efficacy. However, the Phase III studies with anacetrapib were concluded successfully in 2017 whereupon clinical proof of concept was achieved and inhibition of CETP led to an increase in HDL-C and prevention of CHD. ${ }^{13}$

We have disclosed diphenylpyridylethanamine (DPPE) $2^{14}$ and triphenylethanamines (TPE) $3^{15}$ as potent CETP

Received: March 4, 2019

Accepted: April 30, 2019

Published: May 6, 2019 
<smiles>CCOC(=O)N1c2ccc(C(F)(F)F)cc2C(N(Cc2cc(C(F)(F)F)cc(C(F)(F)F)c2)C(C)=O)CC1CC</smiles>

1 Torcetrapib CETP Scintillation Proximity Assay (SPA) $\mathrm{IC}_{50}=0.012 \mu \mathrm{M}$ CETP Human Whole Plasma Assay hWPA IC ${ }_{50}=0.10 \mu \mathrm{M}$<smiles>O=C(NC(Cc1ccccc1)(c1ccc(F)c(OCC(F)(F)F)c1)c1ccc(F)c(OCC(F)(F)F)c1)c1ccc(F)c(C(F)(F)F)c1</smiles>

3

CETP SPA IC ${ }_{50}=0.0040 \mu \mathrm{M}$ CETP hWPA IC ${ }_{50}=0.21 \mu \mathrm{M}$

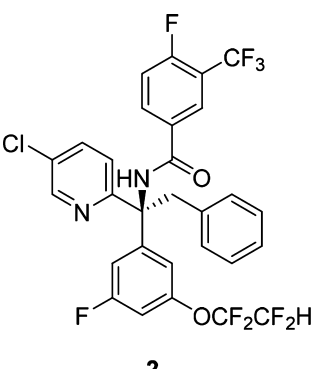

2

CETP SPA IC ${ }_{50}=0.036 \mu \mathrm{M}$ CETP hWPA IC $50=2.8 \mu \mathrm{M}$<smiles>OC[C@H](O)CN[C@](Cc1ccccc1)(c1ccc(F)cc1)c1ccc(Cl)cn1</smiles>

4

CETP SPA IC ${ }_{50}=8.5 \mu \mathrm{M}$

inhibitors (Figure 1). In an effort to further improve the pharmaceutical properties of the compounds in the DPPE and TPE series, while maintaining potency, excellent safety, and PK profile, we continued to explore polar substituents at the $\mathrm{N}$ terminus position. In the course of optimizing the $\mathrm{N}$-terminus hydroxy alkyl amine analogs in the DPPE series, we identified diol, $4^{16}$ (Figure 1), with significantly improved solubility albeit with a very low level of CETP inhibitory activity. However, hydroxyamine 3 (Figure 1) was potent, so we sought to combine the diol moiety with a terminal trifluoromethyl group to increase the potency of the diol analogs. The first analog synthesized to test this hypothesis was the bis trifluoromethyl diol $\mathrm{N}$-terminus amide, 7 .

Synthesis of diol 7 was accomplished from the intermediate chiral amine $\mathbf{5 a},{ }^{17}$ which was converted to the vinylamide $\mathbf{6 a}$ and oxidized to give diol 7 directly. The corresponding monoalcohol $\mathbf{8}$ was prepared from amine $\mathbf{5 a}$ and the commercially available $(4,4,4)$-trifluoromethyl-3-hydroxy-3-trifluoromethyl-1-butanoic acid (Scheme 1).

Simultaneous optimization of the B-ring (Scheme 1) resulted in identification of the 3-fluoro-5-tetrafluoroethoxy substituted aryl group in $\mathbf{5} \mathbf{b}$. The corresponding intermediate vinylamide $\mathbf{6 b}$ was oxidized to epoxides $\mathbf{6 c}$ and $\mathbf{6 d}$. The diastereomers were separated and the single diastereomers treated with ammonia to generate corresponding amino alcohols $9 \mathbf{a}$ and $\mathbf{9 b}$ (Scheme 1).

Figure 1. DPPE and TPE series CETP inhibitors.

\section{Scheme 1. Synthesis of Compounds $6 a-9 b^{a}$}

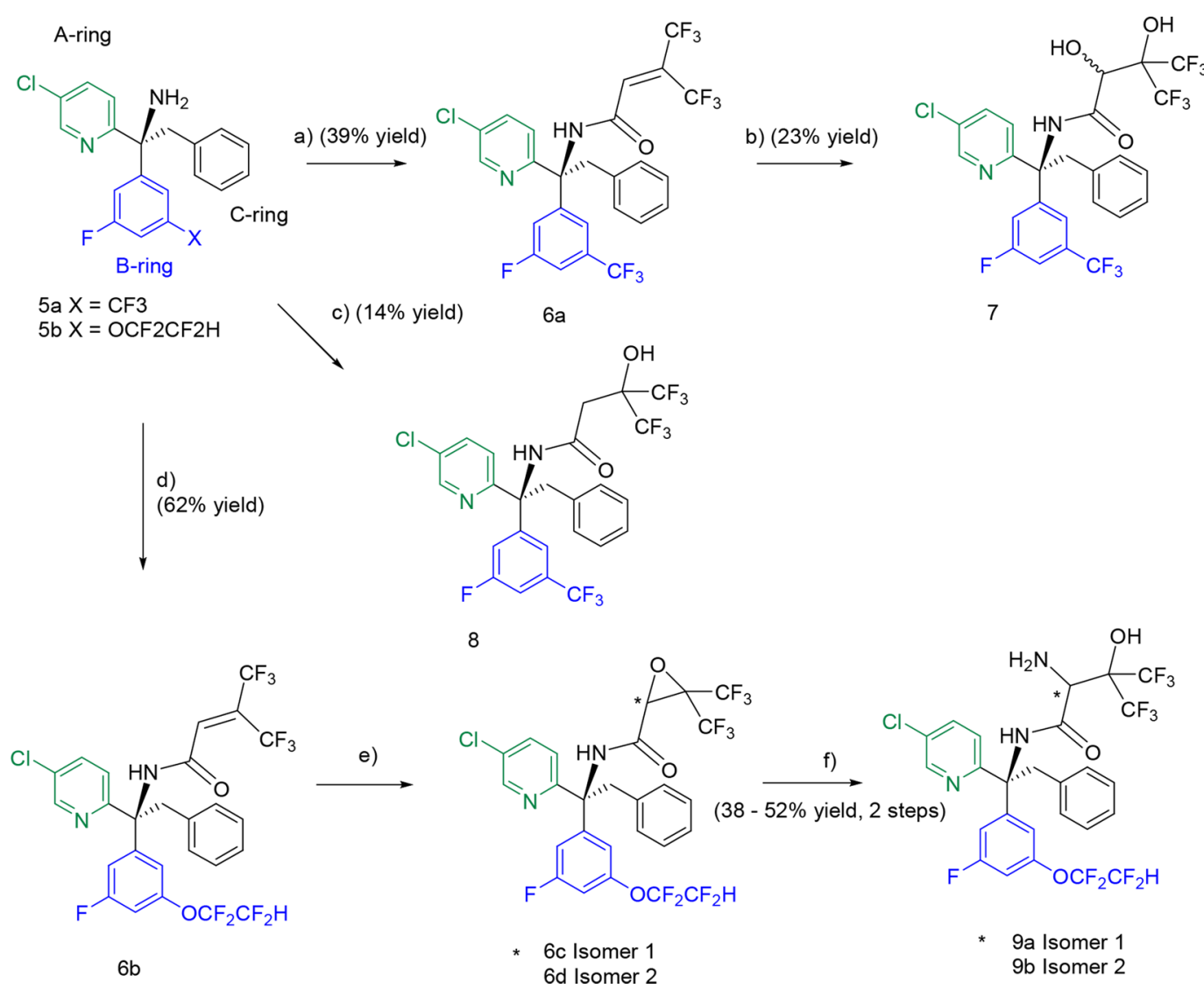

${ }^{a}$ Reagents and conditions: (a) $(4,4,4)$-trifluoro-3-(trifluoromethyl)but-2-enoic acid, isobutylchloroformate, chloroform, $39 \%$ yield; (b) $\mathrm{KMnO}_{4}$, acetone, $\mathrm{K}_{2} \mathrm{CO}_{3}, 23 \%$ yield; (c) (4,4,4)-trifluoromethyl-3-hydroxy-3-trifluoromethyl-1-butanoic acid, IIDQ resin, $\mathrm{MeCN}, 14 \%$ yield; (d) (4,4,4)trifluoro-3-(trifluoromethyl)but-2-enoic acid, IIDQ resin $\mathrm{MeCN}, 62 \%$ yield; (e) $\mathrm{NaOCl}$, pyridine $\mathrm{N}$-oxide, $\mathrm{MeCN}$, chiral separation $\mathrm{ChiralPak} \mathrm{AD}$ (IPA/heptane, 90/10) isomer 1, 6c elution at $46 \mathrm{~min}$ and isomer 2, 6d elution at $65 \mathrm{~min}$; (f) $\mathrm{NH}_{3} / \mathrm{MeOH}, 38 \%$ yield for $9 \mathbf{a}$ and $52 \%$ yield for $9 \mathbf{b}$. 
Scheme 2. Synthesis of Compounds $10 \mathrm{a}-13^{a}$
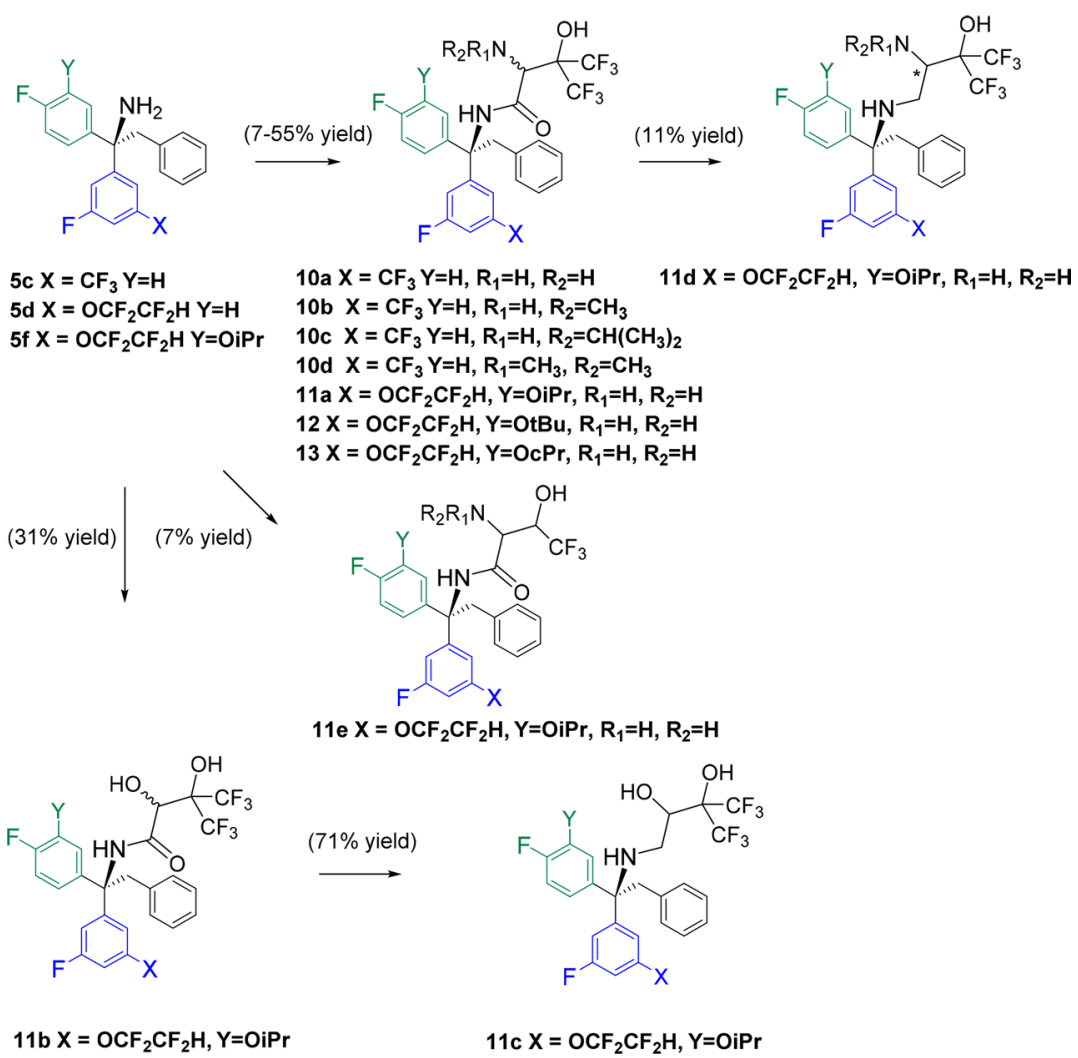

${ }^{a}$ Reagents and conditions: See Supporting Information for reagents, conditions, and individual compound yields.

Table 1. CETP Inhibitory Activity, Microsomal Stability, and $h$ ERG Flux Data for DPPE and TPE Analogs

\begin{tabular}{|c|c|c|c|c|}
\hline compound & $\begin{array}{c}\text { CETP } \\
\text { scintillation } \\
\text { proximity } \\
\mathrm{IC}_{50}(\mu \mathrm{M})^{b}\end{array}$ & $\begin{array}{c}\text { CETP } \\
\text { human } \\
\text { whole } \\
\text { plasma IC } \mathrm{IC}_{50} \\
(\mu \mathrm{M})^{b}\end{array}$ & $\begin{array}{l}\text { liver microsomal } \\
\text { stability }{ }^{c}(\% \\
\text { remaining at } 10 \mathrm{~min}) \\
\text { human, mouse }\end{array}$ & $\begin{array}{l}h \mathrm{ERG} \\
\text { flux } \\
\mathrm{IC}_{50} \\
(\mu \mathrm{M})^{c}\end{array}$ \\
\hline 7 & 0.035 & 1.4 & ND & ND \\
\hline 8 & 0.12 & 3.8 & 92,91 & 22 \\
\hline $9 \mathrm{a}^{a}$ (isomer 1$)$ & 0.053 & 5.9 & 100,100 & $>80$ \\
\hline $9 \mathbf{b}^{a}$ (isomer 2) & 0.080 & 0.94 & 100,100 & $>80$ \\
\hline $10 \mathbf{a}^{a}$ (isomer 2) & 0.011 & 0.43 & 100,72 & $>80$ \\
\hline $10 \mathbf{b}^{a}$ (isomer 2) & 0.14 & 6.2 & 62,87 & 13 \\
\hline $10 c^{a}$ (isomer 2) & 0.23 & 7.1 & 71,54 & 63 \\
\hline $\mathbf{1 0 d}^{a}$ (isomer 2) & 3.3 & 30 & 58,82 & 16 \\
\hline 11a (isomer 1) & 0.003 & 0.056 & 95,90 & 44 \\
\hline $11 \mathrm{~b}$ (isomer 1) & 0.001 & 0.084 & 89,100 & 11 \\
\hline 11c (isomer 1) & 0.005 & 0.058 & 100,100 & 12 \\
\hline 11d (isomer 1) & 0.026 & 0.20 & 81,68 & $>80$ \\
\hline $11 \mathrm{e}$ & 0.006 & 0.27 & 2,16 & ND \\
\hline 12 (isomer 1) & 0.005 & 0.14 & 100,100 & ND \\
\hline 13 (isomer 1) & 0.002 & 0.062 & 100,100 & $>80$ \\
\hline
\end{tabular}

${ }^{a}$ Diastereomers were derived from the corresponding chiral epoxide intermediates. ${ }^{b}$ Scintillation proximity assay and human whole plasma assay $\mathrm{IC}_{50}$ values were measured in duplicate at six concentrations and the mean values were used to calculate $\mathrm{IC}_{50}$ values. ${ }^{c}$ Protocols for assays included in Table 1 are included in the Supporting Information.

We have previously disclosed further optimization of the Aring and the discovery of the more potent TPE series. ${ }^{15}$ Incorporation of the amino-alcohol $\mathrm{N}$-terminus groups into the
Effects of Compounds (Dose Response, p.0.) on CE Transfer Activity in Tg Mice $(n=5)$

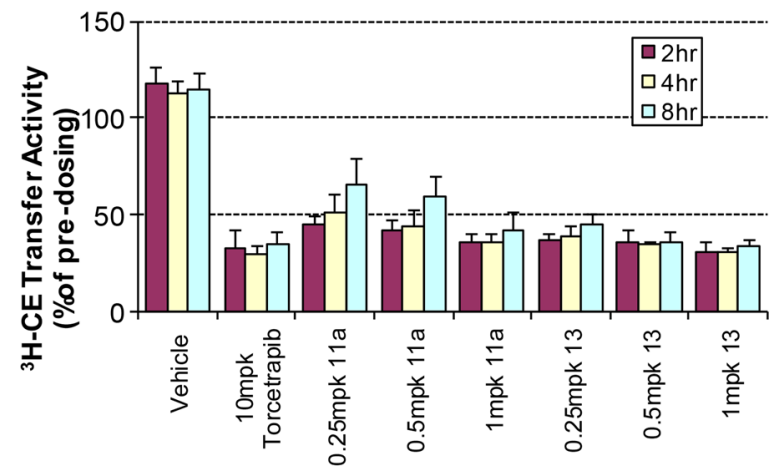

Figure 2. Effects on $3 \mathrm{H}-\mathrm{CE}$ transfer activity in hCETP/apoB-100 dual transgenic mice for $\mathbf{1 1 a}$ and $\mathbf{1 3}$ compared to torcetrapib, $\mathbf{1}$.

4-fluorophenyl substituted TPE series yielded 10a and secondary and tertiary amine analogs $\mathbf{1 0 b}-\mathbf{1 0 d}$ (Scheme 2).

As the A-ring was further optimized for CETP potency, ${ }^{15}$ the 4-fluoro-3-isopropoxy group was identified, and this was subsequently used to prepare analogs 11a to 11e. Combining the 4-fluoro-3-isopropoxy group in the A-ring and the tetrafluoroethoxy group in the B-ring, compound 11a was prepared by the route shown in Scheme 2. Additional SAR at the $\mathrm{N}$-terminus was explored and the diol amide (11b), diol (11c), and amino alcohol (11d) were prepared as described in Scheme 2. Exploring additional alkoxy groups on the A-ring resulted in the tertiary butyl ether (12) and the cyclopropyl ether (13). 
Table 2. Pharmacokinetic Summary for Compounds 11a and 13 in Rat, Mouse, and Monkey ${ }^{a}$

\begin{tabular}{|c|c|c|c|c|}
\hline & $\begin{array}{c}\text { rat } \\
\text { (compound } \\
\text { 11a) }\end{array}$ & $\begin{array}{c}\text { rat } \\
\text { (compound } \\
\text { 13) }\end{array}$ & $\begin{array}{c}\text { mouse } \\
\text { (compound } \\
\text { 13) }\end{array}$ & $\begin{array}{c}\text { monkey } \\
\text { (compound } \\
\text { 13) }\end{array}$ \\
\hline vehicle & $\begin{array}{l}\mathrm{IV}^{b}: \\
\quad \text { Vehicle A }\end{array}$ & $\begin{array}{l}\mathrm{IV}^{b}: \\
\text { Vehicle A }\end{array}$ & $\begin{array}{l}\mathrm{IV}^{b}: \\
\text { Vehicle A }\end{array}$ & $\begin{array}{l}\mathrm{IV}^{b}: \\
\quad \text { Vehicle C }\end{array}$ \\
\hline & $\begin{array}{l}\mathrm{PO}^{c} \text { : } \\
\text { Vehicle A }\end{array}$ & $\begin{array}{l}\mathrm{PO}^{c}: \\
\text { Vehicle B }\end{array}$ & $\begin{array}{l}\mathrm{PO}^{c}: \\
\text { Vehicle B }\end{array}$ & $\begin{array}{l}\mathrm{PO}^{c} \text { : } \\
\text { Vehicle B }\end{array}$ \\
\hline dose $(\mathrm{mg} / \mathrm{kg})$ & $\begin{array}{l}1 \mathrm{IV}^{b} \\
10 \mathrm{PO}^{c}\end{array}$ & $\begin{array}{l}1 \mathrm{IV}^{b} ; 10 \\
\mathrm{PO}^{c}\end{array}$ & $\begin{array}{l}5 \mathrm{IV}^{b} ; \\
10 \mathrm{PO}^{c}\end{array}$ & $1 \mathrm{IV}^{b} ; 5 \mathrm{PO}^{c}$ \\
\hline$V_{\mathrm{ss}}{ }^{d}(\mathrm{~L} / \mathrm{kg})$ & 0.5 & 1.5 & 0.4 & 3.7 \\
\hline $\begin{array}{l}\mathrm{Cl}^{e} \\
(\mathrm{~mL} / \mathrm{min} / \mathrm{kg})\end{array}$ & 5.4 & 2.9 & 1.9 & 0.7 \\
\hline$t_{1 / 2}^{f}(\mathrm{~h})$ & 1.9 & 25 & 5 & 69 \\
\hline$\% \mathrm{~F}^{g}$ & 12 & 39 & 18 & 27 \\
\hline
\end{tabular}

${ }^{a}$ Vehicle A is $10 \%$ Cremophor $/ 10 \% \mathrm{EtOH} / 80 \% \mathrm{H}_{2} \mathrm{O}$; Vehicle B is 15\% Miglyol 812/30\% Capmul MCM/15\% Triacetin/40\% Cremorphor RH40; Vehicle C is $70 \%$ PEG- $400 / 10 \% \mathrm{EtOH} / 20 \% \mathrm{H}_{2} \mathrm{O}$. ${ }^{b}$ Intravenous administration. ${ }^{c}$ Oral administration. ${ }^{d}$ Volume of distribution. ${ }^{e}$ Clearance. ${ }^{f}$ Half-life. ${ }^{g}$ Bioavailability. Additional details available in Supporting Information.

All compounds were assayed for CETP inhibitory activity in the scintillation proximity and whole plasma assays (SPA and WPA, respectively, described in the Supporting Information), and data are included in Table 1.

We were gratified to see that diol amide 7 (SPA IC ${ }_{50} 0.035$ $\mu \mathrm{M})$ was significantly more potent than 4 (SPA IC $508.5 \mu \mathrm{M}$ ); however, further optimization was required to achieve the level of WPA potency observed with the amino alcohol $3 .^{16}$ The corresponding monoalcohol 8 was found to be 3 -fold less potent than diol 7; however, preparation of the amino alcohol $9 \mathrm{~b}$ led to the first submicromolar compounds in the WPA in this series. Consistent with our earlier SAR, the TPE series were more potent than DPPE (e.g., 9b versus 11a). Substitution on the amine resulted in loss in CETP WPA potency (10b, 10c, and 10d). Overall, compound 11a had excellent CETP potency and was advanced to PK/PD studies and safety evaluation. Further modification to the $\mathrm{N}$-terminus resulted in either decreased WPA CETP potency (11d and 11e), decreased liver microsomal stability (11e), or in vitro $h$ ERG liabilities $(\mathbf{1 1 b} \text { and } \mathbf{1 1 c})^{18}$ compared to 11a. Thus, with the $\mathrm{N}$-terminus amino alcohol amide group fixed, further A- ring ether optimization to increase the microsomal stability led to 12 and 13 .

For all amino-alcohols, both diastereomers were synthesized and tested; without exception the most active antipodes were synthesized from the faster eluting chiral epoxide (e.g., 6c, Scheme 1). As described, we were able to determine the absolute stereochemistry at the quaternary center for intermediates $\mathbf{5 a}-\mathbf{f}$; however, we have been unable to obtain a single crystal structure or determine by NMR the absolute stereochemistry of the carbon bearing the amino group in compound 13.

Compounds 11a and 13 were 2 -fold more potent than torcetrapib, 1 in the WPA, had high liver microsomal stability in both mouse and human, and, importantly, did not inhibit $h$ ERG below $44 \mu \mathrm{M}$. Based on the overall profile of these compounds, both 11a and $\mathbf{1 3}$ were advanced to PD evaluation in the hCETP/apoB-100 dual transgenic mouse ${ }^{19}$ (Figure 2). Compound 11a dosed at $1 \mathrm{mg} / \mathrm{kg}$ and compound 13 dosed at $0.5 \mathrm{mg} / \mathrm{kg}$ demonstrated comparable effects on suppression of $\mathrm{CE}$ transfer activity to torcetrapib dosed at $10 \mathrm{mg} / \mathrm{kg}$ in hCETP/apo-B-100 dual transgenic mice (Figure 2). Compound 13 demonstrated a greater effect in this model than compound 11a.

In addition, the exposure profile in rats was higher for compound 13 with bioavailability of $39 \%$ (Table 3). Compound 13 was selected as the lead compound in this series and advanced further to cynomologous monkey PK. We were gratified to observe the improved solubility of compound 13 in vehicles such as $10 \%$ Cremophor: $10 \% \mathrm{EtOH}: 80 \% \mathrm{H}_{2} \mathrm{O}$ which were compatible with our longer term toxicology models and the excellent PK exposure in both rodents and monkeys consistent with an improved pharmaceutical profile for compounds in this series (Table 2). Compound $\mathbf{1 3}$ was also evaluated in the hamster model for CETP efficacy and demonstrated a $32 \%$ increase in HDL cholesterol when dosed at $10 \mathrm{mg} / \mathrm{kg}$ with a plasma exposure of $900 \mathrm{nM}$ (Figure 3.)

In light of the liability profile of torcetrapib with respect to blood pressure elevation and the induction of glucocorticoid and aldosterone synthase ${ }^{20}$ (CYP11B1 and CYP11B2), we tested compound 13 in H295R cells for its ability to increase CYP11B1 and CYP11B2 mRNA levels. Torcetrapib, after $24 \mathrm{~h}$ of incubation, increased expression of the two genes potently (0.002 to $0.006 \mu \mathrm{M})$ and effectively ( $\sim 9$-fold of control for

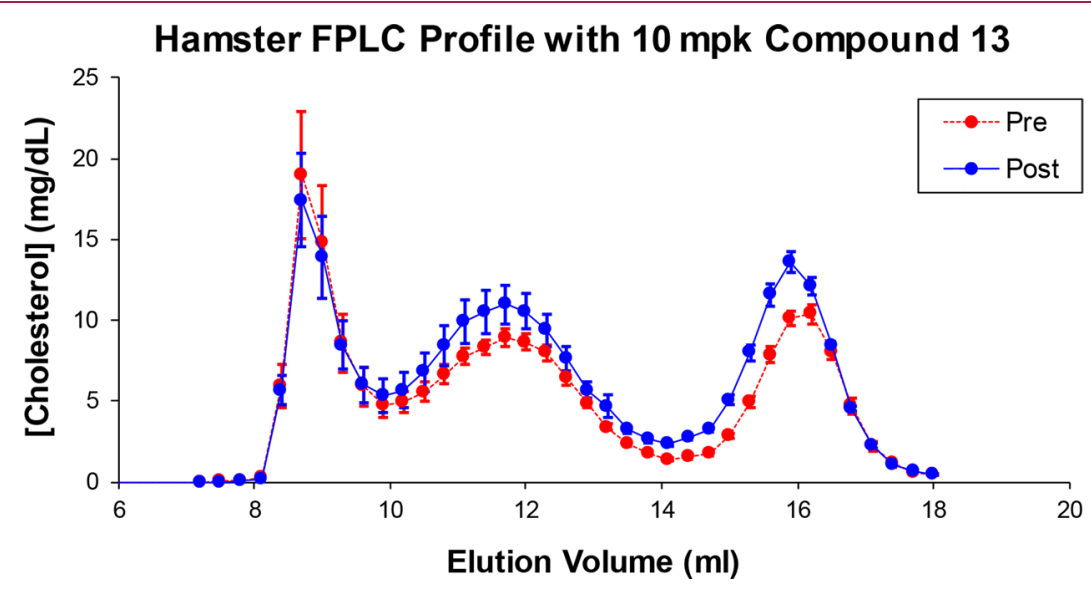

Figure 3. FPLC trace demonstrating effects of compound $13(10 \mathrm{mg} / \mathrm{kg})$ on plasma cholesterol profiles in hamsters (additional details in Supporting Information). 
CYP11B1 and 29 to 68-fold of control for CYP11B2). Angiotensin-II $(0.1 \mu \mathrm{M})$ increased both CYP11B1 and CYP11B2 expression to $\sim 4$-fold of control at $24 \mathrm{~h}$. In contrast, compound 13 did not significantly affect the expression of either CYP11B1 (1.3-fold of control) or CYP11B2 (0.9 to 2.1fold of control) demonstrating that compound 13, at a high concentration $(10 \mu \mathrm{M})$ relative to concentrations that inhibit CETP in plasma $(0.062 \mu \mathrm{M})$, lacks the aldosterone synthase liability of torcetrapib in H295R cells. To further evaluate the cardiac safety profile of compound 13 , a telemetry study was performed in rats dosed at $10 \mathrm{mg} / \mathrm{kg}$, IV $(2.5 \mathrm{mg} / \mathrm{kg}$ infused over $5 \mathrm{~min}$ ), followed by $7.5 \mathrm{mg} / \mathrm{kg} \mathrm{IV} \mathrm{(infused} \mathrm{over} 55 \mathrm{~min}$ ) $(n=7)$. There were no changes in mean, systolic or diastolic $\mathrm{BP}$, heart rate, or locomotor activity at an observed $C_{\max }$ of $23.5 \mu \mathrm{M}$ in the study.

In conclusion, we explored polar groups at the $N$-terminus in the DPPE series and subsequently further optimized the polar groups in the more potent TPE series to identify lead compound 13 with excellent WPA potency and an acceptable in vitro liability profile. PK evaluation of compound 13 in rodents and monkeys in vehicles compatible with longer term toxicology protocols demonstrated an increased vehicle solubility and exposure in both species consistent with an improved pharmaceutics profile. Compound 13 demonstrated robust HDL elevation in both dual transgenic mice and hamster models of efficacy, and significantly, compound 13 did not demonstrate effects on aldosterone synthase in H295R cells or on blood pressure or heart rate in telemetry rats. Given the clinical proof of concept achieved with anacetrapib for elevation of HDL-C through inhibition of CETP, this continues to be an exciting approach to the treatment of $\mathrm{CHD}$.

\section{EXPERIMENTAL SECTION}

Experimental details for synthesis and analysis of compounds $\mathbf{5 a}, \mathbf{5 b}$, $7,8,9 a, 9 b, 10 a-d, 11 a-e, 12$, and 13 can be found in the Supporting Information.

\section{ASSOCIATED CONTENT}

\section{S Supporting Information}

The Supporting Information is available free of charge on the ACS Publications website at DOI: 10.1021/acsmedchemlett.9b00086.

Experimental procedures and analytical data for compounds $\mathbf{5 a}$ to $\mathbf{1 3}$, and in vitro and in vivo assay conditions and protocols (PDF)

\section{AUTHOR INFORMATION}

\section{Corresponding Author}

*Phone: 609-466-5038. E-mail: heather.finlay@bms.com.

\section{ORCID}

Heather J. Finlay: 0000-0003-2309-0136

Notes

The authors declare no competing financial interest.

\section{ACKNOWLEDGMENTS}

The authors would like to acknowledge with thanks Purnima Khandelwal, Tim Gaskill, and Stella Huang for NMR support, Robert Langish for high resolution mass spectrometry support, and Tatyana Zvyaga for providing both profiling data for compounds and protocols.

\section{ABBREVIATIONS}

CETP, cholesterol ester transfer protein; CHD, coronary heart disease; HDL-C, high-density lipoprotein cholesterol; LDL-C, low-density lipoprotein cholesterol.

\section{REFERENCES}

(1) Sacks, F. M. Lipid and lipoprotein metabolism, and risk for cardiovascular disease. Metab. Risk Cardiovasc. Dis. 2011, 18-40.

(2) Kamstrup, P. R. Lipoprotein(a) and ischemic heart disease -A causal association? A review. Atherosclerosis 2010, 211, 15-23.

(3) Dawber, T. R.; Meadors, G. F.; Moore, F. E., Jr Epidemiological approaches to heart disease: the Framingham Study. Am. J. Public Health Nations Health. 1951, 41, 279-281.

(4) Goldenberg, N.; Glueck, C. Statins efficacy, effectiveness and real life goal attainment of statins in managing cardiovascular risk. Vasc. Health Risk Manage. 2009, 5, 369-376.

(5) Ninomiya, H. Niemann-Pick C1-Like 1: a key player in intestinal cholesterol absorption. Yonago Acta Medica 2010, 53 (2), 29-36.

(6) Ansell, B.; Hobbs, F. D. R. The potential for CETP inhibition to reduce cardiovascular disease risk. Curr. Med. Res. Opin. 2006, 22, 2467-2478.

(7) Barter, P. The role of HDL-cholesterol in preventing atherosclerotic disease. Eur. Heart J. Suppl. 2005, 7, F4.

(8) Toth, P. P.; Murthy, A. M.; Sidhu, M. S.; Boden, W. E. Is HPS2THRIVE the death knell for niacin? J. Clin. Lipidol. 2015, 9, 343-350.

(9) Gautier, T.; Masson, D.; Lagrost, L. The potential of cholesteryl ester transfer protein as a therapeutic target. Expert Opin. Ther. Targets 2016, 20, 47-59.

(10) Masson, D. Anacetrapib, a cholesterol ester transfer protein (CETP) inhibitor for the treatment of atherosclerosis. Curr. Opin. Invest. Drugs. 2009, 10, 980-987.

(11) Sahebkar, A.; Simental-Mendia, L. E.; Guerrero-Romero, F.; Golledge, J.; Watts, G. F. Efficacy and Safety of Evacetrapib for Modifying Plasma Lipids: A Systematic Review and Meta-Analysis of Randomized Controlled Trials. Curr. Pharm. Des. 2016, 22, 595-608.

(12) Devaraj, S.; Jialal, I. Novel cholesteryl ester transfer protein inhibitors: Promising therapy for dyslipidemia? Metab. Syndr. Relat. Disord. 2011, 9, 163-165.

(13) Filippatos, T. D.; Kei, A.; Elisaf, M. S. Anacetrapib, a New CETP Inhibitor: The New Tool for the Management of Dislypidemias? Diseases 2017, 5, 21.

(14) Harikrishnan, L. S.; Finlay, H. J.; Qiao, J. X.; Kamau, M. G.; Jiang, J.; Wang, T. C.; Li, J.; Cooper, C. B.; Poss, M. A.; Adam, L. P.; Taylor, D. S.; Chen, A. Y. A.; Yin, X.; Sleph, P. G.; Yang, R. Z.; Sitkoff, D. F.; Galella, M. A.; Nirschl, D. S.; Van Kirk, K.; Miller, A. V.; Huang, C. S.; Chang, M.; Chen, X.; Salvati, M. E.; Wexler, R. R.; Lawrence, R. M. DiPhenylPyridylEthanamine (DPPE) derivatives as cholesterol ester transfer protein (CETP) inhibitors. J. Med. Chem. 2012, 55, 6162-6175.

(15) Qiao, J. X.; Wang, T. C.; Adam, L. P.; Chen, A. Y. A.; Taylor, D. S.; Yang, R. Z.; Zhuang, S.; Sleph, P. G.; Li, J. P.; Li, D.; Yin, X.; Chang, M.; Chen, X.; Shen, H.; Li, J.; Smith, D.; Wu, D.; Leith, L.; Harikrishnan, L. S.; Kamau, M. G.; Miller, M. M.; Bilder, D.; Rampulla, R.; Li, Y.; Xu, C.; Lawrence, R. M.; Poss, M. A.; Levesque, P.; Gordon, D. A.; Huang, C. S.; Finlay, H. J.; Wexler, R. R.; Salvati, M. E. Triphenylethanamine derivatives as cholesteryl ester transfer protein inhibitors: Discovery of $\mathrm{N}$-[(1R)-1-(3-Cyclopropoxy-4fluorophenyl)-1-[3-fluoro-5-(1,1,2,2-tetrafluoroethoxy)phenyl]-2-phenylethyl]-4-fluoro-3-(trifluoromethyl)benzamide (BMS-795311). J. Med. Chem. 2015, 58, 9010-9026.

(16) Jiang, J.; Finlay, H.; Johnson, J. A.; Harikrishnan, L.; Kamau, M.; Qiao, J.; Wang, T.; Adam, L.; Taylor, D.; Yang, R.; Sleph, P.; Chen, A. Y. A.; Yin, X.; Wexler, R.; Salvati, M. E. Discovery of hydroxyl 1,2-diphenylethanamine analogs as potent cholesterol ester transfer protein inhibitors. Bioorg. Med. Chem. Lett. 2016, 26, 32783281. 
(17) Kamau, M. G.; Harikrishnan, L. S.; Finlay, H. J.; Qiao, J. X.; Jiang, Ji.; Poss, M. A.; Salvati, M. E.; Wexler, R. R.; Lawrence, R. M. Synthesis of tertiary carbinamines. Tetrahedron 2012, 68, 2696-2703.

(18) Zhou, Z.; Vorperian, V. R.; Gong, Q.; Zhang, S.; January, C. T. Block of HERG potassium channels by the antihistamine astemizole and its metabolites desmethylastemizole and norastemizole. Journal of Cardiovascular Electrophysiology 1999, 10, 836-843.

(19) Grass, D. S.; Saini, U.; Felkner, R. H.; Wallace, R. E.; Lago, W. J. P.; Young, S. G.; Swanson, M. E. Transgenic mice expressing both human apolipoprotein B and human CETP have lipoprotein cholesterol distribution similar to that of normolipidemic humans. $J$. Lipid Res. 1995, 36, 1082-1091.

(20) Hu, X.; Dietz, J. D.; Xia, C.; Knight, D. R.; Loging, W. T.; Smith, A. H.; Yuan, H.; Perry, D. A.; Keiser, J. Torcetrapib induces aldosterone and cortisol production by an intracellular calciummediated mechanism independently of cholesteryl ester transfer protein inhibition. Endocrinology 2009, 150, 2024-2026. 